\title{
Yumurtacı Tavuk Rasyonlarına Değişik Oranlarda Katılan Humat'ın Yumurta Verimine Etkisinin Gamma ve Mcnally Modelleri ile Analizi
}

\begin{tabular}{|c|c|}
\hline $\begin{array}{l}\text { Araştırma / Research } \\
\text { Geliş Tarihi / Received } \\
\text { 27.08.2017 }\end{array}$ & 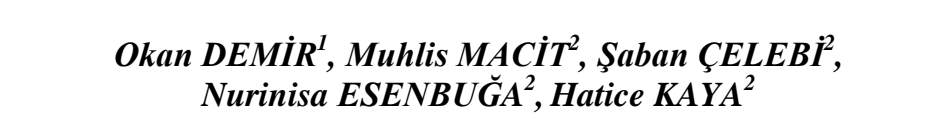 \\
\hline $\begin{array}{l}\text { Kabul Tarih / Accepted } \\
\text { 13.11.2017 }\end{array}$ & $\begin{array}{c}{ }^{I} \text { Atatürk Üniversitesi Ziraat Fakültesi Tarım Ekonomisi Bölümü, } \\
\text { Erzurum- Türkiye }\end{array}$ \\
\hline $\begin{array}{l}\text { DOI } \\
\text { 10.28955/alinterizbd.336269 }\end{array}$ & ${ }^{2}$ Atatürk Üniversitesi Ziraat Fakültesi Zootekni Bölümü, Erzurum- Türkiye \\
\hline $\begin{array}{l}\text { ISSN } 2564-7814 \\
e-I S S N 2587-2249\end{array}$ & *e-posta: okandemir@atauni.edu.tr \\
\hline
\end{tabular}

Öz: Türkiye yumurta üretimiyle dünyanın önemli ülkelerinden birisi olmasına rağmen, toplam üretimi mevcut potansiyeli düzeyinde değildir. Toplam yumurta üretimini artırmanın en etkin yolu verimliklik artışı sağlamaktır. Bu çalışmada yumurtacı tavuk bazal yemine değişik oranlarda humat ilave edilerek oluşturulan rasyonların yumurta verimine etkisi Gamma ve McNally modelleriyle analiz edilmiştir. Yumurtacı tavuk yemine ilave edilen $\% 0,15$ oranında humatın, yumurta verimine en fazla katkıyı sağladığı belirlenmiştir. Sonuç olarak, yumurtacı tavuk yemlerine humat ilavesinin yumurta verimi üzerine etkisine yönelik farklı bölgelerde, farklı tür ve cins kanatılır üzerinde daha fazla ve uzun süreli çalışmaların yapılması önerilmektedir.

Anahtar Kelimeler: Yumurtacı tavuk, Humat, yumurta üretim eğrileri

\section{The Analysis with Gamma and McNally Models of Effect of Different Level Humate Supplemented into Diets of Laying Hen on Egg Production}

\begin{abstract}
Although Turkey is one of the world's most important countries with egg production, total production is not at its current potential. The most effective way to increase total egg production is to increase productivity. In this study, egg production efficiency of rations formed by adding humate to laying hen's basal diet at various ratios was analyzed using Gamma and McNally models. It was determined that humate added at $0.15 \%$ into diet of laying hens gives the maximum contribution to egg production. As a result, it is suggested that further investigations in different regions on different species and breed of poultry are needed to clarify the effect of humate supplemented into diets of laying hen on the egg production.
\end{abstract}

Keywords: Laying hen, Humate, egg production curve

\section{GíRiş}

Türkiye'de yumurta tavukçuluğu sektörü büyümeye açık önemli bir sektördür. Sektör, 98,6 milyon adet yumurtacı tavuk ve 18.7 milyar adet yumurta üretimiyle ekonomiye önemli bir katma değer sağlamaktadır. Türkiye, 1.045 milyon ton yumurta üretimiyle dünyada 9. sırada yer alırken, kişi başına yıllık 200 adet yumurta tüketimiyle 18. sırada yer almaktadır (Anon., 2016). Ancak Türkiye'de kişi başına yumurta tüketimi hala yeterli ve beklenen sayıda değildir (Anon., 2015). Sektörün mevcut altyapısıyla daha yüksek bir katma değer üretmesinin yolu maliyet ve verimlilik üzerine direkt etkili olan yem karmasının optimize edilmesidir.

Çeşitli yem katkı maddelerinin kullanımı, hayvan besleme ve biyoteknoloji alanlarında sağlanan ilerlemelere paralel olarak son yıllarda üzerinde en çok durulan konuların başında gelmektedir.

Son yıllarda yem katk1 maddesi olarak antibiyotikler, hormonlar, organik asitler, enzimler, oligosakkaritler, humatlar ve probiyotikler yemden yararlanmayı artırmak, elde edilen hayvansal ürünlerin miktar ve kalitesini yükseltmek, hayvanların sağlıklarını korumak ve sonuçta elde edilen ürünlerin maliyetini düşürmek amacıyla özellikle kanatlı hayvan rasyonlarında ssklıkla kullanılmaktadırlar. Humatların antibiyotiklere alternatif yem katkı maddeleri olarak kanatlı yemlerinde kullanımları giderek artmaktadır (Aimonen ve Nasi-Rauva, 1991; Veldhman ve Vahl, 1994; Dierck, 1989). 
Humatların yumurta tavuklarında performans üzerine etkilerini ortaya koymak amaciyla yapılan çalışmaların yeni olması ve yeterli sayıda olmaması bu konuda daha fazla sayıda araştırma yapılması gerektiğini ortaya koymaktadır. Buradan hareketle bu çalışmanın amacı; humik, fulvik ve ulmik asitleri ile bir kısım iz elementleri ihtiva eden Farmagülatör dry ${ }^{\mathrm{TM}}$ ' nin yumurtacı tavuk yemlerinde farklı oranlarda kullanılmasının performans üzerine etkilerini belirlemektir. Tavuklarda yumurta üretimi, genellikle nonlinear matematiksel modellerin kullanıldığ 1 yumurta üretim eğrileriyle belirlenmektedir (Miyoshi ve ark., 1996). Bu çalışmada, iki model tipi kullanılarak farklı oranlarda humat içeren rasyonlarla beslenen tavukların yumurta üretim eğrileri karşılaştırılmıştır.

\section{MATERYAL VE YÖNTEM}

Materyal

Hayvan materyali

Araştırmanın hayvan materyalini, Atatürk Üniversitesi Ziraat Fakültesi Araştırma ve Uygulama Çiftliği Tavukçuluk Şubesinde yetiştirilen 46 haftalık yaşta 360 adet Lohmann LSL-beyaz ticari yumurtacı tavuk oluşturmuştur. Deneme Atatürk Üniversitesi Ziraat Fakültesi Araştırma ve Uygulama Çiftliği Tavukçuluk Şubesi kümeslerinde yürütülmüştür. Araştırma boyunca standart yemlik, suluk, aydınlatma ve yoğunluk kullanılmıştır.

\section{Yem materyali}

Yem materyalini, kafes yumurtac1 tavuk yemine $\% 0.15, \% 0.25$ ve- $\% 0.35$ oranında humat (Farmagülatör dry ${ }^{\mathrm{TM}}$ ) ilave edilerek hazırlanan ve bileşimi-kimyasal kompozisyonu Çizelge 1'de verilen rasyonlar oluşturmuştur. Deneme grupları H0 (kontrol), H1(\%0.15), H2(\%0.25) ve H3(\%0.35) şeklinde dizayn edilmiştir.

Çizelge 1. Bazal Yemin Bileşimi, Kimyasal Kompozisyonu ve Kimyasal Analiz Sonuçları

\begin{tabular}{lclc}
\hline Yem Ham Maddeleri & $\begin{array}{c}\text { Karmadaki } \\
\text { Oranı (\%) }\end{array}$ & Kimyasal Kompozisyon & $\begin{array}{c}\text { Besin Madde } \\
\text { Oranı (\%) }\end{array}$ \\
\hline Mısır & 35,12 & Kuru Madde & 88,0 \\
Buğday & 10,0 & Ham Protein & 16,0 \\
Arpa & 15,06 & Ham Selüloz & $\leq 8,0$ \\
Soya küspesi.48 & 14,23 & Ham Kül & $\leq 13,0$ \\
Ayçiçeği küspesi & 4,0 & HCL'de Çözünmeyen Kül & $\leq 1,0$ \\
Et-kemik unu & 2,28 & Lisin & $\geq 0,65$ \\
Hayvansal yağ & 1,34 & Metiyonin & $\geq 0,30$ \\
Fulfatsoya & 8,0 & Sistin & $\geq 0,25$ \\
Mermer tozu & 8,05 & Kalsiyum & $2,5-5,0$ \\
Metiyonin+Lisin & $0,11+0,08$ & Fosfor & $\geq 0,6$ \\
Tuz & 0,25 & Tuz & $\leq 0,40$ \\
Vit. 15/5* & 0,25 & & $\geq 2650$ \\
Na bikarbonat & 0,05 & & \\
Enzim & 0,05 & & \\
Toxin bağlayıcı & 0,1 & & \\
Fitaz & 0,08 & ME Kkal/ kg yem & \\
\hline Kimyasal Analiz Sonuçları & & Besin Madde Oranı (\%) & \\
\hline Kuru Madde & & 90,00 & \\
Ham Protein & & 15,71 & \\
Ham Selüloz & & 4,55 & \\
Ham Yağ & & 2,75 & \\
Ham Kül & & 11,14 & \\
N'siz Öz Maddeler & & & \\
\hline
\end{tabular}

\section{Yöntem}

Deneme gruplarının oluşturulması ve hayvanların beslenmesi

$\mathrm{Bu}$ çalışma, her birinde 90 hayvan bulunan, biri kontrol, üçü deneme grubu olmak üzere toplam 4 grupta, 360 tavuk kullanılarak, tam şansa bağlı deneme planına göre yürütülmüştür. Her grup kendi içerisinde, her birinde 5 hayvan bulunan 18 alt gruba ayrılmış ve üç katlı batarya tipi kafeslere $(50 \times 46 \times 46 \mathrm{~cm})$ şansa bağlı olarak dağıtılmıştır. Kontrol grubu bazal yemle, H1, H2 ve H3 gruplar ise bazal yeme $\% 0.15,0.25$ ve 0.35 düzeylerinde humat ilave edilerek oluşturulan rasyonlarla, bir haftası deneme yemlerine alıştırma periyodu olmak üzere toplam 25 hafta süreyle beslenmişlerdir. 
Hayvanlara yem ve su ad-libitum olarak verilmiştir. Yumurtacı tavuk kümesi günde 17 saat Alinteri aydınlatılmıştır.

\section{Yumurta veriminin belirlenmesi}

$\mathrm{Bu}$ çalışmada performans özelliklerinden birisi olan yumurta verimi ele alınmıştır. Grupların yumurta verimleri, üretilen yumurtalar her gün aynı saatte sayılarak kaydedilmiş ve her hafta sonunda üretilen yumurta sayıları grupta bulunan hayvan sayısına bölünerek adet (adet / tavuk-hafta) olarak ifade edilmiştir.

\section{Yumurta üretim eğrileri}

Çalışmada yumurta verimini optimize eden humat seviyesinin belirlenmesinde yumurta üretim eğrilerinden faydalanılmıştır. Yumurta üretim eğrisi, belli bir zaman peryodu ile bu peryot boyunca üretilen yumurta sayısı arasındaki fonksiyonel ilişkiyi ortaya koymaktadır (Cason and Britton, 1988; Yang ve ark., 1989). Yumurta üretim eğrileri haftalık üretim miktarları esas alınarak elde edilmiştir. Üretim eğrilerinin belirlenmesinde nonlinear regresyon ve hesaplamada Gauss-Newton en küçük kareler yöntemi kullanılmıştır (Hartley, 1961). Nonlinear modeller, yumurta üretim verilerinin fonksiyonel olarak açıklanmasında yaygın bir şekilde kullanılmaktadır (Cason and Ware, 1990; Miyoshi ve ark., 1996; Narushin and Takma, 2003; Savegnago ve ark., 2011). Modellerin hesaplanmasında NLOGIT5 programından yararlanılmıştır.

Yumurta üretim eğrilerinin belirlenmesinde Gamma ve McNally nonlinear modelleri kullanılmıştır (Wood, 1967; McNally, 1971; Narinc ve ark., 2014).

1. Gamma Model:

2. McNally Model:

$$
Y_{t}=a t^{b} e^{(-c t)}
$$

Formüllerde;

$$
Y_{t}=a t^{b} e^{\left(-c t+d t^{\frac{1}{2}}\right)}
$$

a, b, c, d katsayıları,

t süreyi (hafta),

$\mathrm{Y}$ ise yumurta üretimini ifade etmektedir.

\section{ARAŞTIRMA BULGULARI VE TARTIŞMA}

Deneme gruplarına göre haftalık yumurta üretimine ait deskriptif istatistikler Çizelge 2'de verilmiştir. Haftalık yumurta üretiminin en yüksek olduğu grup H1, en düşük olduğu grup ise H3 olmuştur. Deneme süresince en yüksek yumurta üretimine 150,5 adet yumurta ile H1 grubu sahip olmuş, bunu sırasıyla H2, H0 ve H3 grupları izlemiştir.

Çizelge 2. Gruplara Yönelik Tanımlayıcı İstatistikler (adet / tavuk-hafta)

\begin{tabular}{cccccc}
\hline Grup & Ortalama & $\begin{array}{c}\text { Standart } \\
\text { Hata }\end{array}$ & Minimum & Maksimum & $\begin{array}{c}\text { Toplam (Deneme } \\
\text { Süresi) }\end{array}$ \\
\hline H0 & 6,05 & 0,24 & 5,62 & 6,34 & 145,2 \\
H1 & 6,27 & 0,36 & 5,33 & 6,71 & 150,5 \\
H2 & 6,05 & 0,45 & 4,96 & 7,04 & 145,2 \\
H3 & 5,98 & 0,51 & 4,71 & 6,92 & 143,4 \\
\hline
\end{tabular}

Model sonuçları Çizelge 3'de verilmiştir. Her iki model tipinin belirleme katsayısı birbirine yakın olmakla birlikte McNally modelinin açıklama gücü daha yüksektir. Modellerin belirleme katsayıları \%54,3 ile 65,9 arasında değişmektedir. Belirlilik katsayılarının seviyeleri çalışmanın amacı açısından değerlendirildiğinde, modeller arasında karşılaştırma yapılmayıp, gruplar arasında karşılaştırma yapıldığı için çalışmanın amaçlarına uygundur. Her iki modelin sonuçları da birbiriyle uyumludur. Her iki modelde a parametreleri, Gamma modelinde ise c parametreleri önemli bulunmuştur $(\mathrm{p}<0.01)$. Ayrıca Gamma modelinde H1 ve H3 gruplarında b parametreleri \%5 düzeyinde önemlidir.

Matematiksel olarak yumurta üretim eğrileri 3 kısma ayrılmaktadır. Birinci kısım, maksimum üretime ulaşıncaya kadar yükselen trend, ikinci kısım, maksimum verim aşaması, üçüncü kısım ise düşüş trendidir (Fialho and Ledur, 1997). Yumurta üretim eğrilerinin tahmininde kullanılan her iki modelde de "a" parametreleri başlangıç üretimini ifade etmektedir. Gamma modeline göre başlangıç üretimi bütün gruplarda haftalık 6 adedin üzerindeyken McNally modelinde sadece H1 grubu 5,99 adettir. Maksimum üretime ulaşma hızı açısından en avantajlı H3 (0.08397) grubu olurken yumurta üretim 
hızı en yavaş yükselen grup H0 olmuştur. Maksimum üretime en erken ulaşan grup 3,49 hafta ile H0

iken en geç ulaşan grup 4,81 hafta ile H1 grubudur. Maksimum üretimde kalma süresi açısından 2,12 hafta ile $\mathrm{H} 0$ en avantajl grup olurken, bunu sirasiyla 2,03 hafta ile $\mathrm{H} 1,1,98$ hafta ile $\mathrm{H} 2$ ve 1,89 hafta ile $\mathrm{H} 3$ grupları takip etmektedir.

Çizelge 3. Model Sonuçları

\begin{tabular}{|c|c|c|c|c|c|}
\hline \multirow{2}{*}{ Model } & \multirow{2}{*}{ Parametre } & \multicolumn{4}{|c|}{ Tahmini Model Parametreleri } \\
\hline & & H0 (Kontrol) & H1 & H2 & H3 \\
\hline \multirow[t]{7}{*}{ Gamma } & $\mathbf{A}$ & $6,29175^{* * *}$ & $6,38179^{* * * *}$ & $6,31796^{* * * *}$ & $6,18170^{* * * *}$ \\
\hline & & $(0,15884)$ & $(0,17110)$ & $(0,23048)$ & $(0,22344)$ \\
\hline & $\mathbf{B}$ & 0,03082 & $0,05792^{* *}$ & 0,05184 & $0,08397^{* * *}$ \\
\hline & & $(0,02295)$ & $(0,02424)$ & $(0,03327)$ & $(0,03295)$ \\
\hline & $\mathbf{C}$ & $0,00882^{* * *}$ & $0,01203^{\text {**** }}$ & $0,01307^{* * * *}$ & $0,01823^{* * * *}$ \\
\hline & & $(0,00275)$ & $(0,00289)$ & $(0,00400)$ & $(0,00397)$ \\
\hline & Adj. $\mathbf{R}^{2}$ & 0,568 & 0,582 & 0,543 & 0,657 \\
\hline \multirow[t]{8}{*}{ McNally } & A & $\begin{array}{l}7,21901^{* * *} \\
(1,43798)\end{array}$ & $\begin{array}{l}5,99634^{* * *} \\
(1,26394)\end{array}$ & $\begin{array}{l}6,15462^{* * *} \\
(1,79560)\end{array}$ & $\begin{array}{l}6,90372^{* * * *} \\
(1,97816)\end{array}$ \\
\hline & B & 0,13035 & 0,01257 & 0,03291 & 0,16400 \\
\hline & & $(0,14555)$ & $(0,15405)$ & $(0,21235)$ & $(0,20965)$ \\
\hline & $\mathbf{C}$ & $-0,00607$ & 0,01878 & 0,01591 & 0,00621 \\
\hline & & $(0,02158)$ & $(0,02285)$ & $(0,03167)$ & $(0,03120)$ \\
\hline & D & $-0,16393$ & 0,07446 & 0,03123 & $-0,13196$ \\
\hline & & $(0,23616)$ & $(0,024991)$ & $(0,34552)$ & $(0,34042)$ \\
\hline & Adj. $\mathbf{R}^{2}$ & 0,577 & 0,601 & 0,544 & 0,659 \\
\hline
\end{tabular}

Parantez içindeki değerler standart hatalardır. Not: ***, **, * ==> Önem Seviyesi 1\%, 5\%, 10\%

Yumurta üretim eğrileri Şekil 1'de verilmiştir. Her iki modelin grafik sonuçları benzerlik göstermektedir. Regresyon eğrileri ortalamalardan geçtiği için toplam ve ortalama yumurta üretimi en yüksek olan H1 grubunun yumurta üretiminde avantajlı olduğu görülmektedir. 


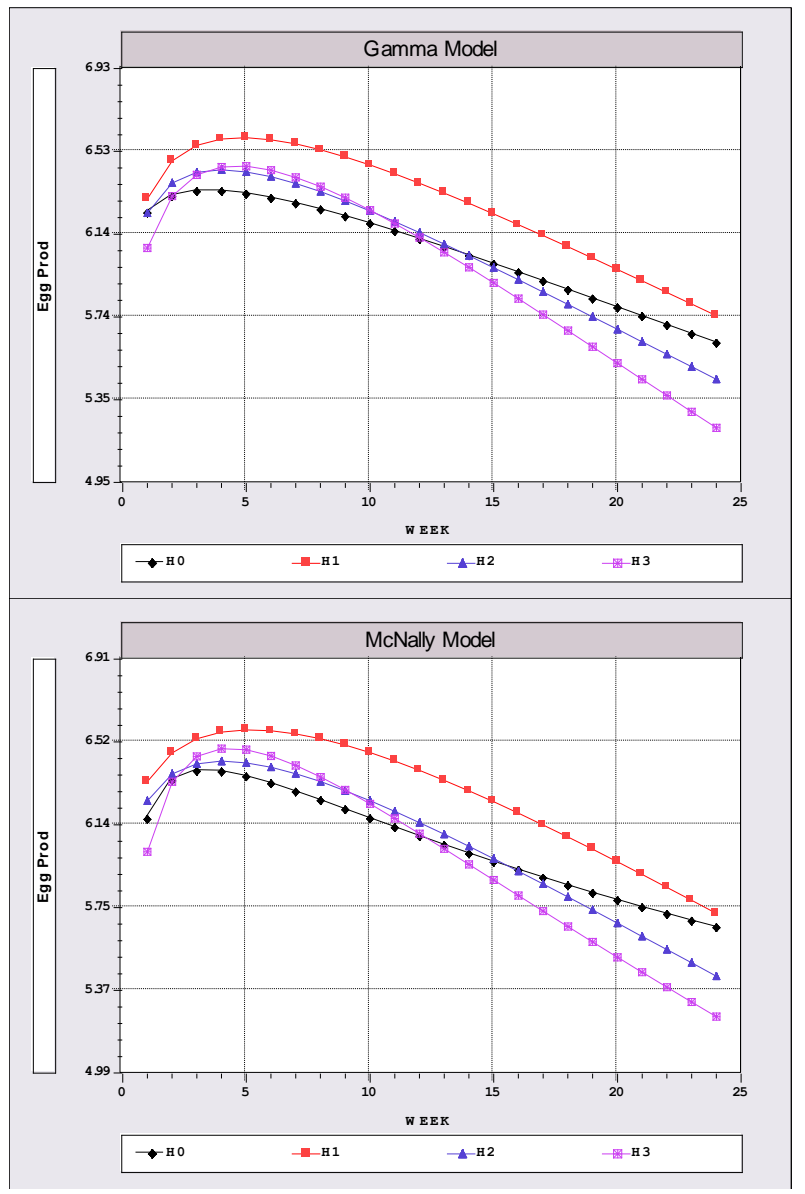

Şekil 1. Gamma ve McNally Modellere göre yumurta üretim eğrileri

\section{SONUÇ VE ÖNERILER}

Yumurtacı tavuk bazal yemine farklı oranlarda humat ilave edilerek, oluşturulan rasyonların yumurta verimi üzerine etkilerinin belirlendiği çalışmada, yumurta verimini, yeme $\% 0,15$ oranında ilave edilen humat yükseltmiş̧tir. Oluşturulan yumurta üretim eğrilerine göre de en avantajlı grup H1 olmuştur.

Sonuç olarak, yumurtacı tavuk yemlerine humat ilave edilmesine yönelik farklı bölgelerde, farklı tür ve cins kanatlılar üzerinde daha fazla ve uzun süreli çalışmaların yapılması gerektiği kanaatine varılmıştır.

\section{TEŞEKKÜR}

$\mathrm{Bu}$ çalışmada, TUBITAK tarafindan desteklenmiş olan VHAG-1968 no'lu projenin verileri kullanılmıştır.

\section{KAYNAKLAR}

Aimonen, E.M.J., Nasi-Rauva, E., 1991. Replacement of barley by oats and enzyme supplementation in diets laying hens. 2. Interior quality and chemical composition of eggs. Acta Agric. Scand., 41, 193-205.

Anonim, 2015. Türkiye Yumurta Sektörü. TMMOB Ziraat Mühendisleri Odası Sektör Raporu, Ankara.

Anonim, 2016. Yumurta Tavukçuluğu Verileri, 2016. Yumurta Üreticileri Merkez Birliği (Yum-Bir), Ankara.

Cason, J. A., Britton, W. M., 1988. Comparison of compartmental and Adams-Bell models of poultry egg production. Poultry Science 67: 213-218.

Cason, J. A., and G. O. Ware. 1990. Analysis of flock egg production curves using generalized growth functions. Poult. Sci. 69:1054-1069.

Dierck, N. A., 1989. Biotechnology aids to improve feed and feed digestion: enzymes and fermentation. Arch. Anim. Nutr. Berl., 39, 241-261.

Fialho, F. B., and M. C. Ledur. 1997. Segmented polynomial model for estimation of egg production curves in laying hens. Br. Poult. Sci. 38:66-73.

Hartley, H. O. 1961. The modified Gauss-Newton method for the fitting of nonlinear regression functions by least squares. Technometrics 3:269-280.

McNally, D. H., 1971. Mathematical model for poultry egg production. Biometrics 27: 735-738. 
Miyoshi, S., Luc, M.K., Kuchida, K., Mitsumoto, T., 1996. Application of Nonlinear Models to Egg Production Curves in Chickens. Jpn. Poult. Sci., 33:178-184.

Narinc D., Uckardes F., Aslan E., 2014. Egg production curve analysis in poultry science. World Poultry Sci. J., 70: $817-828$.

Narushin, V. G., and C. Takma. 2003. Sigmoid model for the evaluation of growth and production curves in laying hens. Biosystems Eng. 84:343-348.

Savegnago, R. P., B. N. Nunes, S. L. Caetano, A. S. Ferraudo, G. S. Schmidt, M. C. Ledur, and D. P. Munari. 2011. Comparison of logistic and neural network models to fit to the egg production curve of White Leghorn hens. Poult. Sci. 90:705-711.

Veldhman, A., Vahl, H.A., Xylanase in broilerdiets with differences in characteristics and content of wheat. Br. Poult. Sci., 35: 537-550, (1994).

Wood, P. D. P., 1967. Algebraic model of the lactation curve in cattle. Nature 216: 164-165.

Yang, N., Wu, C., McMillan, I., 1989. A new mathematical model for poultry egg production. Poultry Science 68: 476-481. 